\title{
El Proceso Populista: un aporte teórico al debate del fenómeno
}

\author{
The Populist Process: A theoretical contribution to the debate \\ of the phenomenon
}

\author{
Claudio Riveros F*
}

\begin{abstract}
Resumen: Aun cuando podría definirse el populismo como un juego discursivo (subsumido en lógicas equivalenciales y diferenciales) de tipo hegemónico entre el pueblo y el bloque de poder, en este artículo, se concibe al populismo como un proceso histórico que obedece a distintas condiciones de posibilidad. Se argumenta que todo proceso populista requiere de una articulación discursiva y de profunda movilización en un contexto de crisis hegemónica. Conceptualmente ello se traduce en la existencia de un momento, fenómeno y un régimen populista.
\end{abstract}

Palabras claves: Populismo, Laclau, Proceso Populista

\begin{abstract}
Although the Populism would be defined as a hegemonic discursive "game" (subsumed in different-equivalent logics) between the people and the power spheres; in this article, Populism herein is understood as a historical process that would occur under certain conditions. It is argued that any populist process needs a context of hegemonic crisis and deep mobilization. Conceptually, this means that there is a populist moment, phenomenon and regime.
\end{abstract}

Keywords: Populism, Laclau, Populist Process

Recibido: 14 abril 2017

Aceptado: 27 agosto 2017

"Chileno, Doctor en Sociología. Profesor Universidad Andrés Bello, Escuela de Sociología, Facultad de Humanidades y Ciencias Sociales. cla.riveros@uandresbello.cl 


\section{Introducción}

En la actualidad, el populismo se ha vuelto una palabra cotidiana. Un término que de tanto uso ha perdido todo rigor conceptual, pues ya no solo es aplicable a fenómenos políticos determinados, que con razón o no, son calificados como poco democráticos, sino que su uso se ha extendido de tal manera en el vocabulario, que populismo viene a significar el síntoma que expresaría una enfermedad que carcome el escenario político. En efecto, el populismo se ha terminado por identificar con clientelismo, despilfarro económico, engaño, demagogia, mentira y falsa democracia. En una palabra: el populismo se ha convertido en un insulto. Como bien sintetiza María Esperanza Casullo, “existen pocos conceptos sobre los que exista tan nulo consenso académico (...) podríamos decir, exagerando un poco, con que nadie sabe bien qué es el populismo, pero casi todos coinciden en que es malo" (Casullo, 2014: 281).

De hecho, una de las dificultades más acuciantes en el estudio del populismo ha sido compatibilizar el marco teórico con su aplicación empírica. Pues, por lo general, se ha resuelto esta problemática considerando un factor específico como desencadenante del populismo, o bien se han concebido modelos altamente acumulativos que no permiten distinguir el peso específico de determinados factores, y que apuntan más bien a detectar rasgos o la presencia de "síntomas" que hacen plausible la existencia del "fenómeno"1 (Weyland, 2001).

Así, entonces, debido a la dificultad de que los académicos lleguen a un acuerdo sobre lo que es posible calificar como populismo y de que éstos renuncien a su propia conceptualización, es que, a nivel teórico, se propone conceptualizar al populismo como un proceso, distinguiendo entre un momento, un fenómeno y un régimen populista. Por cuanto más allá de que uno u otro investigador califique de populista a un líder o a un discurso, ya sea porque hay un número objetivo de características que le permitan constatar su presencia, lo que se propone este estudio, es concebir al populismo como un proceso histórico que obedece a distintas condiciones de posibilidad de tipo estructural y agencial. A nivel empírico, en tanto, la propuesta que aquí se presenta tiene la ventaja no solo de ser aplicable al estudio de casos, sino que implica, de paso, evitar categorizaciones muchas veces ideológicas que se imponen sobre el populismo antes de estudiarlo empíricamente.

La presente propuesta, entonces, se propone estudiar al populismo desde una perspectiva sociológica-histórica y no episódica. Llamar a un "fenómeno populista" desde uno u otro enfoque no está en discusión (aunque acá se asume el político-discursivo), sino el verificar que un fenómeno populista se desencadena tras un momento populista, y que luego, puede constituirse en un régimen que responde a distintos contenidos (derecha o izquierda) $)^{2}$.

Con todo, hay que tener en consideración que no existe una trayectoria única o una explicación total para entender al populismo (Quiroga, 2014), y por lo mismo, este artículo no tiene como objetivo principal, el proponer una teoría general sobre el tópico, como

\footnotetext{
${ }^{1}$ Vale la pena aclarar que cuando utilizo el término fenómeno entre comillas, lo hago tan solo para reemplazar el término populismo, y por lo mismo, hago la distinción con la noción fenómeno en el entendido del populismo como proceso, cuestión que se clarificará más adelante.

${ }^{2}$ Tanto la noción de proceso, momento, fenómeno y régimen son utilizados en cursiva solo en la introducción, con el fin de destacar la presente propuesta, mas, en el desarrollo de la tesis, se usan sin cursiva.
} 
tampoco pretender que un académico renuncie tajantemente a su forma de conceptualizarlo. Más bien, se hace una propuesta que busca acotarse empíricamente a experiencias históricas concretas. De este modo, la apuesta es mucho más reducida que el desarrollo de un modelo comparativo, pero no por ello es menos compleja y ambiciosa.

La primera parte del artículo tiene como objetivo principal explicar al lector la problemática subyacente al populismo como marco de análisis. Luego, en una segunda parte, se explica brevemente lo propuesto por Ernesto Laclau, pues se conserva de él la noción de articulación discursiva, pero se le "supera", ya que se invita a reflexionar respecto a las distintas condiciones de posibilidad de tipo estructural (sin que por ello se realice un análisis puramente estructuralista) y agencial que tiene el populismo. En consecuencia, en esta combinación de articulación, contenidos, discurso y condiciones de posibilidad, se recupera parte de la producción teórica (sociológica) latinoamericana de 1960, con el objeto de lograr un anclaje socio-material al post-estructuralismo discursivo de Laclau. Es a partir de dichos enunciados que, en una tercera parte, se intenta hacer un aporte teórico, proponiendo que el populismo se debe reconocer como un proceso, que contiene un momento, fenómeno y un régimen. Finalmente, hago presente al lector que, por razones de espacio, se ha limitado el estudio del problema a cuestiones teóricas sin llevar a cabo un estudio empírico del proceso populista. En este sentido, se espera, por una parte, presentar un segundo artículo sobre la materia; y por otra, que sean también otros los investigadores que puedan llevar a cabo dicha tarea ${ }^{3}$.

\section{I-. Estado de la Cuestión}

\section{1-. Presentación del problema}

Dos son los principales problemas que se deben resolver cuando se quiere estudiar en profundidad el populismo: uno es de tipo metodológico, el otro, teórico. En primer lugar, a nivel metodológico, la dificultad consiste en la insalvable distancia que se presenta, en los distintos trabajos existentes sobre la materia, entre teoría y práctica. Así, lo que ha predominado hasta el momento es, por una parte, la ejecución de análisis empíricos que parten desde definiciones abstractas del populismo que poco tienen que ver con la realidad, $\mathrm{y}$ en donde se proponen teorías generales aplicables a todo evento, sin importar mayormente el contexto histórico o el área geográfica. Por otra, la comparación empírica se ha superpuesto de tal modo a la teoría, que se corre el riesgo de que el concepto pierda su carácter esencial, pues, lo que importaría, serían las "enunciaciones" (según el enfoque que se siga, claro está) de populismo y no el proceso que acaece. Es decir, ante el afán de demostrar que se está en presencia de populismo, se podría caer en una tipología indeterminada de casos, pues de lo que se trataría, en último término, sería verificar los distintos grados de populismo y no precisar o explicar el por qué un proceso político-social puede ser catalogado de populista.

${ }^{3}$ Con todo, el autor de este artículo concluyó el año pasado su tesis doctoral en donde analiza teórica y empíricamente (aplicándolo al caso de Chile) estas materias. 
Un segundo problema que se presenta, es de tipo teórico, esto es, determinar cuáles son los elementos y características constitutivas del populismo. Cas Mudde en conjunto con Cristóbal Rovira (2012), han puesto énfasis en señalar que uno de los dilemas fundamentales respecto a la comprensión del populismo, es que los investigadores ni siquiera se han puesto de acuerdo en decidir qué clase de cosa es, cuestión que traería como consecuencia, la constante ramificación de teorías abstractas y cuando no de posiciones ideológicas que se alejan de la realidad.

Una buena síntesis teórica de las explicaciones que se han esbozado para responder a la pregunta sobre qué es el populismo y que permite introducir de buena manera los distintos enfoques existentes, es lo planteado por Kurt Weyland (2001), quien distingue tres formas de explicar el fenómeno populista: la estrategia acumulativa, estrategia de adición y estrategia de redefinición. Por acumulativa, entiende el autor una definición que combina la presencia de atributos de diversos ámbitos, tales como discursivos, políticos, económicos y sociales. En este sentido, se estaría ante la presencia del populismo cuando dichas características comparecen en conjunto y la ausencia de alguna de ellas denotaría, por consiguiente, un objeto distinto de estudio. De todos modos, el predominio de la variable socio-económica (modernización, industrialización, migración) sería decisiva y se conjugaría con elementos propios de la política (discurso ambiguo, alianza multiclasista, estilo político, entre otros) (Weyland, 2001). La estrategia de adición, en tanto, conecta los atributos de los distintos dominios, por lo que más que utilizar una lógica "y", opera con una lógica "o", es decir, basta con que uno de esos atributos de dominio esté presente para que se constate el concepto. Argumenta Weyland (2001) que esta estrategia, que denomina en último término "radial", no permite clarificar de qué trata realmente el populismo, puesto que solo estaría proponiendo una definición mínima que establecería la presencia de innumerables subtipos de populismo. En rigor, no habría que ser muy perspicaz para darse cuenta de que esta estrategia conlleva una proliferación de excepciones en el mismo momento de su aplicación empírica. Por último, la estrategia de redefinición, que defiende Weyland, formula la utilización de un solo campo de dominio, descartando cualidades u otros atributos que no serían esenciales, inclinándose el autor por una explicación política, específicamente en su caso particular, de concebir al populismo como una particular estrategia política (Weyland, 2001).

A partir de estas distintas estrategias, es posible clasificar, en la literatura especializada, diferentes enfoques que intentan definir el populismo: primero, el enfoque macro sociológico-histórico, ya sea que explique al populismo como una transición a la modernidad (Germani, 1965a, 1965b; Di Tella, 1965) o como un modelo socio-económico de desarrollo en un contexto específico (Ianni, 1975; Vilas, 1995a, 1995b; Weffort, 1968); segundo, el enfoque relacional que concibe al fenómeno como un tipo específico de estilo político (Conniff, 2003, 2012; Freidenberg, 2012; Hermet, 2003, 2008; Ostiguy, 2014, 2015); tercero, el enfoque institucionalista, que entiende al populismo como una estrategia de poder (Navia, 2003; Roberts, 1995, 2009; Walker, 2006, 2009; Weyland, 1999, 2001, 2003, 2004); cuarto, el enfoque economicista, que opone populismo a una economía de libre mercado (Dornbush y Edwards, 1991; Edwards, 2009); en quinto lugar, el enfoque ideológico o ideacional, que explica el populismo como una ideología maniquea (Mudde (2004); Mudde y Rovira, 2011, 2012, 2017; Rovira, 2012, 2013); y en sexto lugar, el 
enfoque político-discursivo, que entiende al fenómeno como una lógica discursiva (Laclau, 1986, 2005, 2006, 2009, 2010).

Ahora bien, como es imposible realizar un estudio acucioso (además de innecesario) de los distintos enfoques arriba reseñados, es que se ha decidido explicar de modo general (y sin entrar en mayores discusiones teóricas) la propuesta de Laclau, pues como se señaló en la introducción del trabajo, este artículo inicia su análisis desde el planteamiento lacloneano, pero intentando resolver la problemática de que el populismo es solo forma. En rigor, aquí se hace una apuesta conceptual en la que se le intenta dar un anclaje sociomaterial al post-estructuralismo discursivo de Laclau, aunque conservando su lógica articuladora.

\section{2-. Enfoque político-discursivo Lacloneano: algunas notas relevantes}

El trabajo de Ernesto Laclau respecto del populismo se construye a partir de una crítica profunda del modo en que ha sido estudiado el concepto, principalmente, por la vaguedad teórica que ha asumido y porque ha sido permanentemente catalogado como 'la enfermedad político-social' que evitaría el auténtico desarrollo democrático y el despegue económico de los países en crecimiento. Para el intelectual argentino, en cambio, todo análisis que gire en torno al populismo debería poner énfasis en tres puntos que lo definen:

En primer lugar, en determinar qué es lo propiamente discursivo del populismo antes de asignarle características o elementos que le sean propios a todo evento. Pues, en su opinión, el populismo es una categoría ontológica y no óntica, ya que más que determinar los contenidos que participan del proceso de articulación -léase lo económico, político e ideológico-, se debería observar el modo en el que se articulan contenidos sociales que producen efectos y que se manifiestan, principalmente, en modos de representación. En efecto, Laclau parte desde la base de que las prácticas políticas no expresan la naturaleza de los agentes sociales, sino que, en cambio, los constituyen. Así, más importante que enfocarse en la conformación de los grupos, se debería mostrar principal atención en el análisis de las prácticas, puesto que todo grupo social no es más que una articulación de prácticas sociales (Laclau, 2009). Su propuesta, entonces, tiene un carácter formal, en el sentido de que todos sus rasgos definitorios están relacionados con un modo de articulación específico - la prevalencia de la lógica equivalencial por sobre la lógica de la diferencia-, independientemente de los contenidos reales que se articulan. En consecuencia, "un movimiento no es populista porque en su política o ideología presenta contenidos reales identificables como populistas, sino porque muestra una determinada lógica de articulación de esos contenidos - cualesquiera sean estos últimos" (Laclau, 2009: 53).

De hecho, para Laclau, la característica invariante de todo populismo reside en que es un fenómeno ideológico en el cual las interpelaciones popular-democráticas se articulan y se presentan hegemónicamente bajo la forma de un antagonismo irreductible respecto de la ideología dominante. Por lo tanto, si el populismo es per se contrahegemonía, todo proceso político que cuestione la ideología hegemónica y/o dominante es populismo, independientemente de su 'color' político. En consecuencia, desde la perspectiva del autor, el populismo podría provenir desde las más diversas orientaciones políticas, pues lo que realmente importa para calificar a un fenómeno como populista es la presencia de una 
frontera antagónica que enfatiza la radicalidad popular, en razón de que los canales existentes para la vehiculización de las demandas sociales han perdido toda eficacia y legitimidad (Laclau, 2005, 2009).

En segundo lugar, y directamente relacionado con lo anterior, Laclau está muy lejos de considerar el populismo como una enfermedad política; muy por el contrario, la lógica populista, en tanto asume la constitución del pueblo, es la forma como se construye lo político y se vive en democracia. Desde esta perspectiva, el populismo no es un momento de transición hacia la madurez política, sino una permanente acción de la dimensión política $^{4}$. La lógica populista viene a ser, entonces, un acto performativo de la realidad social, que está dotado de una racionalidad propia y que simplifica el espacio político en dos dicotomías antagónicas y cuyos dos polos son necesariamente imprecisos: la elite y el pueblo $^{5}$.

La construcción del pueblo -esgrime Laclau- se efectúa en y cómo discurso, en un plano relacional objetivo. El pueblo, no sería más que una relación real entre los agentes sociales; de la interrelación existente entre los distintos grupos en razón de constantes luchas hegemónicas. Laclau divide al grupo social-como pueblo- en unidades menores, que llama demandas. La lógica populista es, a fin de cuentas, una articulación de demandas que transita entre la lógica de la diferencia y la lógica de la equivalencia y que tienen como característica esencial el encontrarse en oposición al orden establecido. Es decir, pese a que la realidad social se construye a partir de dos grupos antagónicos, la homogeneidad del pueblo no es un dato de la causa; por el contrario, si éste se constituye a partir de una lógica discursiva, el grupo -como pueblo- siempre estará dividido en distintos grupos particulares heterogéneos. Entonces, solo a partir de la diferencia del grupo en tanto demanda (s) (heterogeneidad/homogeneidad), es que se construye hegemónicamente la equivalencia del grupo como un todo (Laclau, 2005).

En consecuencia, no existe para Laclau un elemento central que determine en última instancia lo que es el pueblo, puesto que las diferencias son equivalentes entre sí (nunca iguales) en su rechazo común a la identidad excluida. La equivalencia es precisamente lo que subvierte la diferencia, de manera que toda identidad es construida de esta tensión entre la lógica de la diferencia (demanda democrática) y de la equivalencia (demanda popular). Mas, va a ser una diferencia, que nunca va a dejar de lado su particularidad, la que asuma la representación (por la imposibilidad conceptual de aprehender totalmente el objeto) de una totalidad inconmensurable; es, precisamente, una parte que representa al todo (sinécdoque). "De esta manera la operación en la que una particularidad asume una significación universal inconmensurable consigo misma es la que denominamos hegemonía" (Laclau, 2005: 95). De todos modos, se debe tener claro que la diferencia y la equivalencia están presentes tanto en la lógica populista como institucionalista, por lo que la diferencia entre ambas lógicas se debe buscar al nivel de los significantes hegemónicos que estructuran la formación discursiva. Un discurso "institucionalista es aquel que intenta hacer coincidir los límites de la formación discursiva con los límites de la comunidad (...) En el caso del

\footnotetext{
${ }^{4}$ En rigor, no deja de ser interesante que Laclau retomara y profundizara, casi cuarenta años después, el núcleo central del argumento de Worsley (1969) respecto al populismo, esto es, la dimensión (lógica) política del fenómeno.

${ }^{5}$ Por supuesto que lo esencial aquí es la oposición antagónica, esto es, bloque de poder/los de abajo; por lo tanto, la elite puede ser denominada oligarquía, clase política, mientras que los de abajo se pueden asociar a los desamparados o desvalidos.
} 
populismo ocurre lo opuesto: una frontera divide a la sociedad en dos campos" (Laclau, 2005: 207).

De hecho, plantea Laclau, es el discurso institucionalista el que reclama la diferencialidad como el único equivalente legítimo, asumiendo y -de paso- exigiendo que todas las diferencias sean aceptadas y validadas en una totalidad más amplia: una totalidad de diferencia, siempre favorable al núcleo de poder; mientras que, en la lógica populista, hay una parte que exige ser el todo, dando paso a la exclusión radical en el espacio comunitario mediante la construcción de dos fronteras antagónicas irreductibles, que se enfrentan alrededor de dos cadenas equivalenciales incompatibles (Laclau, 2005: 107-108). Dicho de otro modo, es en la totalidad nunca totalizada donde hallamos una tensión inacabable, una pulsión hacia una totalidad siempre fallida, pero necesaria, pues sin ella no habría identidad. Ello, porque Laclau parte de la base que hay una asimetría entre la comunidad como un todo (sociedad) y el actor social que opera en ella. Por lo tanto, no existe actor social -incluso como pueblo- cuya voluntad coincida con la sociedad concebida como totalidad, aunque exija serlo. El punto de Laclau, entonces, es que no existe ningún medio que permita salvar el abismo entre la voluntad política y el espacio comunitario, pero que el intento "por construir ese puente define la articulación específicamente política de las identidades sociales" (Laclau, 2009: 54).

Con todo, Laclau enseña que es durante la lucha hegemónica que una particularidad se elevará como un significante vacío, que intenta poseer una dimensión de plenitud de la comunidad: "Los significantes vacíos sólo pueden desempeñar su rol si significan una cadena de equivalencias, y sólo si lo hacen constituyen pueblo. En otras palabras, la democracia sólo puede fundarse en la existencia de un sujeto democrático, cuya emergencia depende de la articulación vertical de demandas equivalentes" (Laclau, 2005: 215). Así, el significante vacío representa el procedimiento en el que una demanda particular (a condición que nunca abandone dicha particularidad) pasa a representar la cadena como totalidad, de un modo hegemónico. Es, entonces, un particular que se vacía y que al universalizarse cubre un espacio más vasto que el de su propia particularidad, pues articula elementos heterogéneos de un modo hegemónico. De ahí que se entienda la pobreza de sus símbolos, pues tiene que brindar homogeneidad equivalencial a una realidad altamente heterogénea. Siendo ineluctable que, en este proceso, lo que gane en extensión lo pierda en intensidad.

Así, entonces, en una construcción populista clásica, la dicotomía entre la elite y el pueblo es siempre antagónica y se manifiesta mediante demandas. Para Laclau, toda demanda varía entre la petición y el reclamo, ya que toda vez que una petición no ha sido satisfecha ésta adquiere el carácter de un reclamo profundamente democrático, pues conserva la noción de insatisfacción con respecto al statu quo (Laclau, 2005: 161). Precisamente, el no reconocimiento de demandas por parte del poder institucionalizado, es lo que permite la unión de diversas demandas populares unidas, todas ellas, por una lógica equivalencial que, en definitiva, propiciará el advenimiento del pueblo tras una lucha hegemónica, logrando así la construcción de una demanda popular que unificará al pueblo frente a un enemigo común, el bloque de poder. En consecuencia, no se puede producir una lógica equivalencial sin una heterogeneidad de demandas insatisfechas, por lo que una de las estrategias del poder institucional será, precisamente, identificar la demanda y tratar de 
satisfacerla o domesticarla, rompiendo la cadena en alguna de sus partes, aunque sin lograr que ésta desaparezca para siempre.

En definitiva, para Laclau, el pueblo se construye sobre la base de un conjunto de demandas no satisfechas que se diferencian unas de otras, pero que logran su equivalencia en torno al significante vacío. Según esta perspectiva de análisis, entonces, el pueblo no se podría identificar con una parte de la sociedad, ni mucho menos con una clase en particular. Si las demandas son representativas de los distintos grupos que conforman a la sociedad éstas mutarán conforme al paso del tiempo; por lo tanto, la demanda de un grupo que dé paso a la construcción del significante vacío nunca se fijará en el tiempo.

Es por este motivo que, según Laclau (2005), la plenitud no es más que un objeto del deseo y sólo es posible en sociedades donde no hay política. El fin -trágico- de la política, se produciría cuando predomine un discurso en el que la lógica pura de la diferencia (institucionalista) o bien en el que la lógica de la equivalencia (discurso populista) se impongan de un modo excluyente; es decir, cuando una de las dos lógicas se imponga y aplaste a la otra. Esto es lo que explicaría, por ejemplo, por qué fracasa la consolidación de un pueblo en momentos que ha habido una "movilización populista", ya que el pueblo podría desintegrarse en la institucionalidad, constituirse como una eterna diferenciación o bien totalizarse como plenitud.

Advierte Laclau, que la relación entre política y populismo es manifiesta, pues en ambos procesos hay una división de la sociedad y un demos ambiguo que es, por un lado, un sector dentro de la comunidad (los no reconocidos), y por el otro, un actor que se representa a sí mismo, de modo antagónico, como la totalidad de la comunidad. Entonces, si la política exige la división social, el antagonismo, la lógica populista, no sería más que "el modo" de construir lo político. En la construcción de una frontera de exclusión, que divide a la sociedad en dos campos antagónicos, el pueblo sería algo menos que la totalidad de los miembros de la comunidad; no obstante, es un componente parcial que aspira a ser concebido como la totalidad, única y legítima. Por supuesto que, sin una ruptura en el orden social, no habría posibilidad de antagonismo. Lo decisivo, como argumenta Laclau, es la construcción de un pueblo, en donde se nominaliza a esa plenitud que por mucho tiempo estuvo ausente, aunque paradójicamente siempre estuvo presente, ya que ese populus, es la fuente actual de opresión (Laclau, 2005). Dicho de otro modo, según Laclau, aquello que se presenta antes de la construcción de la "razón populista", como populus, no es más que una falsa totalidad, pero que, a partir de una lógica discursiva-populista, se constituirá como plebs; es decir, el significante encargado de articular y representar un conjunto de demandas parciales en una totalidad plena: un populus verdaderamente universal que es negado por el orden -institucional- existente.

En tercer lugar, si el pueblo dista de ser tan sólo una expresión ideológica, sino que, por el contrario, es el vínculo lógico que desarrollan los agentes sociales y la forma en específico que se vinculan los distintos grupos, resulta perentorio la presencia de un significante vacío que le confiera cohesión a la heterogeneidad del grupo. Según Laclau, en no pocas ocasiones, este significante vacío estaría representado, nominalizado en la figura de un líder, quien irrumpe en el espacio público para ayudar a fijar la unidad de una formación social en un objeto que sea conceptualmente aprehensible. En rigor, la nominación y el afecto, se transforman en el cemento de unidad, aquel lazo en el que 
destaca la figura del líder como ente unificador. Si la presencia de un líder fuerte se explica, según Freud (2010), porque un número mayoritario de individuos han puesto el mismo y único objeto en el lugar de su yo ideal, logrando siempre la identificación completa entre sí en su "yo común”, Laclau (2005), por el contrario, postula que el líder sólo será aceptado si presenta de un modo particularmente marcado los rasgos que comparte con aquellos que se supone que debe liderar (como primus inter pares), pues ese rasgo común, que hace posible la identificación entre los miembros del grupo, no puede consistir exclusivamente en el amor hacia el líder, sino en un rasgo positivo compartido por el líder y los liderados ${ }^{6}$. El líder, entonces, pertenecería y encarnaría al pueblo en un doble movimiento, en donde "representante y representado se co-constituyen" (Disch, 2015: 44) en oposición antagónica a la elite.

\section{II-. El proceso populista: momento, fenómeno y régimen}

\section{1-. Notas aclaratorias}

Pese al gran despliegue conceptual, uno de los grandes problemas de catalogar al populismo únicamente como una lógica discursiva, es la dificultad de aplicar empíricamente elementos como ruptura, apelación a los de abajo, dicotomización del campo político a la experiencia histórico-social. Sobre todo, "al momento de sistematizar una explicación que pudiese dar cuenta de las complejidades y contradicciones de los movimientos y regímenes populistas realmente existentes, debido a la heterogeneidad de estos últimos" (Burdman, 2009: 617). Pero la dificultad incluso persiste respecto al tipo de objeto del cual el populismo efectivamente trata; en otras palabras, qué es lo que el investigador va a catalogar de populista, siendo que éste puede tratarse de un tipo de discurso, una dimensión discursiva o un tipo de régimen político con un discurso específico. Entonces, el problema se debería circunscribir en establecer, primero, qué objeto concreto se determinará como populista, y segundo, qué características permitirían legitimarlo como tal (Burdman, 2009). El punto no es menor si se toma en consideración el excesivo formalismo del populismo asumido por Laclau, pese a su posterior apertura y aportes de sus discípulos, en lo referente a la especificidad de sus contenidos (Aboy Carles, 2003, 2005, 2010a, 2010b, 2015; Barros, 2006a, 2006b, 2009, 2014; Burdman, 2009).

Es por estas razones que se ha planteado que la mayor problemática en la propuesta de Laclau, es al momento de generar una conexión más efectiva con la experiencia históricosocial. Y es precisamente en este contexto donde se elabora la propuesta, la cual se propone establecer una mayor conexión entre contenido y forma en el marco de una nueva interpretación teórico-empírica. En rigor, aquí se propone, en primer lugar, que el populismo no puede ser solo forma si no que también contenido, ya que, si se lo considera, esencialmente, como un producto de la lógica política, esto podría inducir a que el término pierda especificidad y se transforme en un concepto híbrido que puede ser aplicado indistintamente a distintos procesos históricos y termine asociándose a la política, al antagonismo y a la hegemonía. De hecho, Melo y Aboy Carlés (2014) sostienen en La

${ }^{6}$ A mayor abundamiento, véase Biglieri y Perelló (2015), como también Tarizzo (2015). 
Razón Populista, "que la cuestión histórica pasa a ser comandada por un análisis de orden cuasi superficial que, con muy poco detalle, intenta englobar procesos muy disímiles que van desde el boulangerismo al kemalismo turco sin un profundo desarrollo. Las experiencias históricas, en el último Laclau, pasaron a ser meras ilustraciones de una demostración lógica previa. Muy distinto a lo que fue su empresa inicial, a mediados de los años 70" (Melo y Aboy Carlés, 2014: 411). En segundo lugar, también se argumenta que si lo único que importa es la articulación discursiva para afirmar que se está ante un movimiento populista, se desconocería el hecho de que elementos estructurales son fundamentales para explicar un proceso social, cuestión que desde un análisis sociohistórico es imposibles de soslayar.

Esto último es particularmente importante, pues la apuesta, en este trabajo, es que los populismos se definan tanto por su articulación como por sus contenidos, apostando a establecer una exploración empírica de los populismos "realmente existentes". En consecuencia, la propuesta que aquí se hace, a nivel conceptual, es que el populismo, pese a que se articula discursivamente también responde a condiciones de posibilidad en tanto combinación de agencia y estructura. Condiciones que no solo permiten su existencia, sino que también pueden bloquear u obturar su desarrollo. No obstante lo anterior, esto no significa que el lector vaya a encontrar a continuación el desarrollo de leyes generales que le permitan advertir o reconocer la presencia o ausencia de populismo, como si hubiese una trayectoria única o una explicación total. Muchos menos se debería esperar el desarrollo minucioso de una tabla de variables, donde se especifiquen las medidas o valores de éstas, que permita medir con precisión distintos grados de populismo.

No se intenta aquí, entonces, hacer una teoría general del populismo, sino que más bien se hace una propuesta teórica que se acota empíricamente al estudio de países en contextos determinados. Por cierto que esta propuesta podría provocar más de alguna crítica (de algún discípulo o continuador de Laclau), pues teóricamente resulta difícil conciliar elementos estructurales con el postestructualismo lacluniano. Pero como bien afirma Aboy Carlés, tal vez la solución a dicha dificultad se encuentre, precisamente, en tratar de hibridar la teoría de Laclau con otros autores y poner en cuestión algunas de sus prenociones teóricas y metodológicas (Aboy Carlés, 2015) ${ }^{7}$.

Es por los motivos antes expuestos, que cifro mi interés, a nivel teórico, en proponer la existencia de un proceso populista, compuesto por un momento, un fenómeno y un régimen. Así, entonces, se invita a reflexionar acerca del populismo respecto a sus condiciones de posibilidad de tipo estructural (sin que por ello se realice un análisis puramente estructuralista) y agencial, evitando así definir al "fenómeno" solo como la lógica de la política, aunque rescatando, por una parte, la idea de que el populismo es una dimensión de la política (Worsley, 1969; Laclau, 2005). Por otra, conservando -de manera importante- la noción de articulación discursiva propuesta por Laclau, al menos en lo que

\footnotetext{
${ }^{7}$ Sobre estos tópicos gira la interesante entrevista que se le hace a Aboy Carlés (2015), uno de los especialistas más importante de Ernesto Laclau (aunque él ha sido criticado con fuerza durante los últimos años por haberse apartado teóricamente de Laclau). En dicha entrevista, Aboy Carlés expresa que una de las principales críticas que le podría hacer no tanto a Laclau si no a sus discípulos y continuadores, es el uso demasiado dogmático de la propuesta (más allá de sus aciertos y debilidades), por cuanto "el estudio específico del campo toma la forma de casi una postal para demostrar el resultado de una prenoción teórica" (185). Así, entonces, según el autor, muchos discípulos y continuadores de Laclau tienen miedo, primero, a pelearse con la teoría en el campo, y segundo, a estar dispuestos a encontrar huecos en la teoría y tratar de hibridarlos con otros autores, cuestión que significaría poner incluso en cuestión algunas prenociones teóricas-metodológicas (186)
} 
dice relación con la configuración del momento y del fenómeno populista, pero no así en la noción de régimen, pues en estos aspectos, este artículo supera ampliamente el marco teórico lacloneano. A decir verdad, en esta combinación de articulación, contenidos, discurso y condiciones de posibilidad, se recupera parte de la producción teórica (sociológica) latinoamericana de 1960, con el objeto de lograr un efectivo anclaje sociomaterial al post-estructuralismo discursivo de Laclau.

A nivel empírico, en tanto, la propuesta que aquí se presenta tiene la ventaja no solo de ser aplicable al estudio de casos, sino que implica, de paso, evitar categorizaciones muchas veces ideológicas que se imponen sobre el populismo antes de estudiarlo empíricamente. Llamar a un "fenómeno" populista desde uno u otro enfoque, no está en discusión (aunque acá se asume el político-discursivo), sino el verificar que dicho fenómeno se desencadena tras un momento populista, y que luego, puede constituirse en un régimen que responde a distintos contenidos. Y eso es justamente la superación de concebir al populismo como una articulación discursiva, porque, en último término, sí importa saber a qué visión de mundo responde, y conocer cuáles fueron los marcos políticos, sociales e ideológicos que entraron en crisis.

\section{2-. El populismo como proceso: una articulación discursiva contra-hegemónica}

Todo proceso populista nace a partir de una crisis hegemónica, ya sea que ésta se encuentre obturada, larvada; o en pleno desarrollo. A lo más podría ocurrir que una crisis hegemónica se pueda estar produciendo paralelamente a una articulación discursiva, pero en el caso de que esta última no se ocasione por un momento populista, dicho discurso podría ser solo calificado de populista en "el papel" (y esto lo digo sin ánimo alguno de descalificar un enfoque en particular). Me explico, una cosa es que un discurso pueda ser catalogado de populista porque reúne características "objetivas" que le permitan llevar ese apelativo (porque hay un líder que se dirige a las masas y porque hay un claro discurso antagónico que separa al pueblo del bloque de poder, entre otras cosas), pero lo que realmente debería importar al momento de constatar la presencia o no de populismo, es si efectivamente el discurso que se enuncia resume una articulación discursiva que intenta o lleva a cabo un proyecto contra-hegemónico. Y esto es solo posible de verificar si se entiende al populismo como un proceso.

Tal como lo manifestaran Laclau y Mouffe (2010), el carácter discursivo de una realidad social, asume que ningún objeto podría emerger al margen de una superficie discursiva. Por lo mismo, no se yerra al afirmar que el discurso político resalta como el principal elemento, si se quiere verificador, de la presencia de una articulación populista. Con todo, esto no significa que sea el discurso el que determina por sí solo si se está ante la presencia o no de populismo. Y esto es importante destacar, no solo porque todo discurso debe trasuntar hacia la "realidad material", sino porque puede darse la situación que comparezcan elementos populistas que no se aducen con la realidad contingente, más allá de si se llevan o no a la práctica en tanto régimen. Por lo mismo, existe un paso intermedio que se debe tener en cuenta a la hora de calificar un proceso como populista, que es, precisamente, lo que determina que se está o no ante un fenómeno populista. Vale decir, un discurso puede ser caracterizado, por ejemplo, por distintos enfoques como populista, pero no por ello se está 
ante un proceso populista ${ }^{8}$. Cuestión distinta es que dicho discurso se articule como acicate o resultado de una crisis hegemónica, pues solo ahí se da inicio a un proceso populista (en tanto fenómeno), aunque no por ello el proceso se cerrará -siempre- con la consolidación de un régimen.

Por cierto que todos los discursos responden a procesos históricos de larga data, pero lo que habría que indagar en los procesos populistas es, precisamente, en aquellos discursos que contribuyen a dislocar el escenario político en la medida que polarizan y ponen en jaque al modelo cultural y político existente. Entonces, al ser todo proceso discursivo una combinación entre estructura y acontecimiento, en éste no solo existe una transmisión de información que se quiere descifrar, sino que también -y más todavía en un discurso populista- ocurren una serie de identificaciones de los sujetos que importa reconocer. Por de pronto, no es que se precise una búsqueda de verdad oculta en un "texto" o en otro, que permita afirmar con toda claridad, como una especie de "medidor", si se está o no ante un discurso populista. Lo que importa, por el contrario, es determinar la dimensión política populista que adquiere el discurso político significando o re-significando contenidos que, en un determinado momento, son simbolizados y adquieren un sentido diferente. Por ende, de lo que se trata, es verificar e interpretar en determinados discursos, "efectos de sentido que son producidos en condiciones determinadas" (Orlandi, 2012: 36), pues el populismo va necesariamente imbricado a un discurso político, "al punto de que su sentido y significado más profundo no puede ser aprehendido sin la comprensión y las premisas y silogismos que componen dicho discurso" (Martínez y Vairberg de Lustgarten, 2014: 468).

En este sentido, es preciso reparar en la apuesta que hace Pelfini (2015) en relación a la existencia de un momento populista, es decir, al contexto de una crisis hegemónica que vendría siendo el gatillante principal del populismo ${ }^{9}$. Con todo, y pese a la presencia de objetivas condiciones que podrían dar lugar a un proceso populista, puede ocurrir que producto de estructuras, repertorios y ausencia de liderazgos, dicho momento no cristalice como fenómeno ni mucho menos como régimen.

Un fenómeno populista, en tanto, requiere de dos condiciones para su existencia: una crisis hegemónica y una articulación populista. Así, entonces, lo que resulta decisivo a la hora de hablar de un fenómeno populista, es que se produzca una articulación populista; esto es, que exista una interrelación necesaria y suficiente entre pueblo, líder, irrupciónruptura, movilización y reconocimiento, en un contexto de crisis hegemónica (presente o incubada) y en tanto el discurso adquiera una dimensión contra-hegemónica.

Ciertamente que una articulación populista se puede generar sin que quien la propugne llegue al poder, mientras que un régimen populista exige de su presencia. Pero no por ello se puede concluir que un régimen populista es ipso facto un fenómeno populista que ha llegado al poder. Existen, en consecuencia, sutiles pero importantes diferencias entre ambos. Un régimen populista a diferencia de un fenómeno populista, exige dos cosas: primero, que intente hacer efectivo (en tanto proyecto contra hegemónico) política e institucionalmente su contenido, cuestión que, por cierto, no debería confundirse con

\footnotetext{
${ }^{8}$ A modo de hipótesis se podría afirmar que tan solo se estaría presente ante un discurso con un marcado lenguaje populista.

${ }^{9}$ Respecto al término "momento populista", hay distintos autores que lo han utilizado, pero ninguno de ellos ha teorizado al respecto. Así, por ejemplo, en distintas entrevistas Chantal Mouffe (2015) ha llamado la atención sobre el "momento populista", queriendo decir con ello un punto de inflexión democrático (populista) en tiempos de post-política. Mientras que Martínez y Vairberg (2014) identifican, en la práctica, el momento populista con el de movilización populista.
} 
cumplir taxativamente "su programa"10; y segundo, que combine (en una sola lógica) tanto la lógica movilizadora como institucional (Ostiguy, 2014).

Se podría incluso decir que la irrupción, la ruptura y la resignificación de símbolos o significados mediante un significante vacío en un contexto de crisis, se define, finalmente, por la forma de sus interpelaciones y no por el principio que las articula, por lo que a priori "toda ideología puede, en este sentido, recurrir a interpelaciones populistas" (Burdman, 2009: 618). Como apunta Burdman, el populismo exige una ruptura con el orden dominante, mas no necesariamente debe significar una transformación progresiva de la sociedad. Y eso - pienso- solo es comprobable en un régimen, pues éste solo lo será en la medida que lleva a cabo su proyecto contra-hegemónico en oposición al bloque histórico de poder, pudiendo acentuar aún más la crisis hegemónica. No es lo mismo, como apunta Melo, manifestar que el populismo "es un discurso de confrontación asociado a un desvalido como sujeto o agente histórico natural que decir, de otra parte, que el populismo es una interpelación democrática-popular desafiante del poder político vigente" (Melo, 2011: 60).

No pudiendo ahondar en una posible distinción entre un populismo de izquierda de otro de derecha ${ }^{11}$, la tipificación presentada más arriba, esto es, la disociación establecida entre un momento, de un fenómeno y un régimen populista, no puede ser vista como una simple tipología. Todo lo contrario, en mi opinión, resulta vital para precisar el concepto, por cuanto el populismo es un tipo de discurso político (en tanto dimensión de la política) que, como régimen, se ha dado en contados y específicos momentos de la Historia. Lo que puede haber existido, quizás, y en no pocas ocasiones, son momentos populistas, pero no así fenómenos que hayan concluido en regímenes populistas. En efecto, resulta perentorio separar tres esferas distintas: la primera, la presencia de una crisis hegemónica (el momento populista); la segunda, que dice relación al tiempo en que se produce la articulación populista (el fenómeno populista), y por último, el proceso de obtención del poder (el régimen populista).

Ciertamente que a nivel conceptual el modelo propuesto, para un lector avezado, podría resultar de gran rigidez al momento de aplicarlo empíricamente, por lo que habría de verificar en el proceso histórico si las fases son siempre secuenciales o si permiten combinaciones aleatorias. Con todo, la clasificación que aquí se presenta tiene cuatro ventajas: primero, por más que se evidencien en un futuro combinaciones aleatorias de las fases éstas siempre serán distinguibles teóricamente; segundo, se evita calificar un sinnúmero de subtipos de procesos históricos, líderes y discursos como populismos (cuestión que no hace más que diluir el concepto); tercero, esta propuesta complementa mediante condiciones de posibilidad- la tesis lacluniana de que el populismo se define

\footnotetext{
${ }^{10}$ Con todo, no es correcto sostener que un régimen populista es todo aquel que no cumple con sus promesas de campaña, como lo afirman algunos investigadores (Hermet, 2003; Walker, 2009). A decir verdad, y si se me permite expresar esto con total franqueza, tal disquisición es demasiado simple, pues bastaría con poner sobre la mesa varios ejemplos actuales (y pasados) para contrastar promesas de campaña y cumplimiento de éstas. En este sentido, de aceptar la hipótesis anterior, el populismo sería casi la condición de la política. Por cierto un exceso por donde se le mire.

${ }^{11}$ Como hipótesis se podría sugerir que, si bien el populismo de derecha podría llevar consigo la promesa rupturista de una auténtica crisis hegemónica, no significaría más que, en último término, un aggiornamento del actual sistema imperante. En otras palabras, los populismos de derecha serían mucho más proclives a mantener el statu quo o exigir la vuelta a un orden tradicional (perdido), enfatizando la retórica, la manipulación y el nacionalismo; por el contrario, un régimen populista de izquierda, llevaría consigo la idea y cuando no el logro de imponer una nueva hegemonía. Los populismos de izquierda, entonces, serían necesariamente transformadores e incluso radicales, pues tendrían la intención de imponer un horizonte de valores distinto al que está vigente.
} 
esencialmente una articulación discursiva; y cuarto, al distinguir entre momentos, fenómenos y regímenes populistas, se consigue explicar que el populismo es un proceso socio-político.

En consecuencia, entiendo por proceso populista, un movimiento nacional-popular en el que se moviliza, mediante un líder, a un pueblo que pone en entredicho, por medio de una ruptura antagónica y una lógica polarizadora, el estado natural de cosas vigente. Movilización popular que está en permanente tensión para lograr su institucionalización, ya que está en busca de un reconocimiento que por mucho tiempo le fue negado. Todo ello, en un contexto de crisis hegemónica.

\section{3-. Las características articulatorias del populismo y sus condiciones de posibilidad}

\section{Impronta nacional-popular}

Que los populismos sean catalogados como movimientos nacional-populares no es producto del azar ${ }^{12}$. Una importante línea teórica, re-inaugurada varios años atrás por Emilio de Ípola, arguye que los populismos conformaron movimientos de nacionalización y ciudadanización de las masas que reconfiguraron, al menos en un principio, lo que hasta ese momento era entendido por lo nacional (de Ípola, 1995). Sin embargo, esta línea teórica fue poco desarrollada por de Ípola, ya que su interés era demostrar que los populismos realmente existentes, rápidamente perdían el espíritu movilizador en aras de un fuerte Estado capitalista dominante, en donde lo nacional-popular pasaba a ser dominado sin contrapeso por lo nacional-estatal. Siguiendo muy de cerca la teoría marxista, de Ípola sostiene que el problema que es intrínseco al populismo, es que la nación encuentra su materialidad en y por el Estado (de Ípola, 1995). Pero más allá que sea la vinculación entre nación y Estado en que el capitalismo adquiere su legitimidad, la hipótesis a sugerir, en este ámbito, es que los populismos intentaron de un modo u otro construir, reconstruir o, al menos, poner en escena, el rol del Estado Nacional.

Afirma Hugo Cancino que los populismos fueron movimientos nacionales-populares (Cancino, 2012) ${ }^{13}$ que deconstruyeron los símbolos, imaginarios y mitos del Estado Nacional Oligárquico en aras de la constitución de una nación a partir del pueblo. "Los actores de esta reconstrucción del Estado Nacional y de su imaginario son las grandes mayorías de la población que quedaron excluidas de una forma del Estado elitista" (Cancino, 2012: 238). Así, para el autor, los movimientos populistas, por un lado, reafirmaron el principio de la "soberanía popular" (en tanto derecho que tienen todos los pueblos de poder decidir sobre su sistema político y el uso de sus recursos naturales), y por otro, son movimientos que desligitimaron la construcción de un Estado Nacional de tipo oligárquico, que solo incluía a los descendientes peninsulares y excluía a las grandes mayorías por el color de su piel. No resulta extraño, entonces, que la nación chilena, argentina u otra, fuera en definitiva, la nación criolla (Cancino, 2012). Por cierto que no en

\footnotetext{
${ }^{12}$ En rigor, el primer autor en utilizar el término nacional-popular fue Gino Germani (1967a), quien aludía a los movimientos movilizadores y fundacionales que se generaron en América Latina, en el marco de un proceso de ruptura con el Estado y la Nación oligárquica.

${ }^{13}$ Cancino (2012) prefiere utilizar este término y no populismo por la contaminación ideológica de este último, que lo ha hecho perder su carácter particular y que lo ha igualado sin más a un discurso demagógico.
} 
todos los países latinoamericanos ocurrió el mismo proceso, pero no se está muy lejos de la verdad afirmar que el imaginario nacional y toda la simbología que conlleva la conformación de los Estados Nacionales, fue construido e impuesto, principalmente, por las elites oligárquicas y sin mayor contrapeso de otras clases sociales hasta el primer tercio del siglo XX. Precisamente fue la aparición de los movimientos nacional-populares, los que ayudaron a socavar las bases materiales, políticas y sociales de la oligarquía. De hecho, Cancino no tiene duda en afirmar que los movimientos populistas, fueron un fenómeno recurrente en la historia de América Latina del siglo XX y que gracias a ellos se podrían explicar las revoluciones y los movimientos sociales. "Ellos son la forma más profunda y radical en que el pueblo ha construido su identidad frente al anti-pueblo, las elites del poder y el sistema de dominación" (Cancino, 2012: 239).

Así también, en un sugerente artículo, "Sobre alquimistas e imaginadores. Populismo y nación", Julio Aibar, propone entender a los populismos "como un síntoma, una problematización y/o una puesta en acto de la llamada cuestión nacional" (Aibar, 2008: 161). Según el autor, los populismos en relación a la cuestión nacional tendrían una doble faceta, pues, por un lado, propugnarían una mayor participación en la construcción de lo nacional, ya sea porque la nación soberana, como comunidad imaginada, no se habría visto directamente involucrada o porque simplemente lo nacional le resultaría espurio. Pero, por otro lado, también podría ocurrir lo contrario; a saber, que un movimiento populista no hiciera más que catalizar y reafirmar la cuestión nacional. Afirma con gran lucidez Aibar Gaete, que el populismo,

es una expresión política que surge ahí donde las personas ya no reconocen mutuamente sus derechos y obligaciones en tanto miembros de una comunidad políticamente imaginada y en el que el ejercicio de la soberanía perdió legitimidad en tanto se fracturó el sentimiento de pertenencia. En algunos casos los mencionados populismos simplemente expresan ese estado, en otros encarnan proyectos políticos de reconfiguración imaginaria de la sociedad" (Aibar, 2008: 167).

Desde esta perspectiva, resultan dos posibles vías de análisis: una, que considera al populismo como un movimiento que enfatiza la construcción de lo nacional-popular, en las que no hay un ataque total a las bases del capitalismo, sino que se exige la reestructuración de la sociedad para otorgar una mayor participación económica (distributiva) y participativa (democrática); de otra, que cataloga al populismo como una particular forma de compromiso estatal de los sectores dominantes o hegemónicos, más precisamente, como un reacomodo de éstos sectores. Es decir, si para algunos el Estado resuelve en nombre de la totalidad nacional las contradicciones, para otros, en cambio, el inconveniente sigue en pie: lo nacional ya le fue dado, principalmente, por el grupo dominante. En términos simples, lo nacional-estatal dominante, sería hegemónico frente a lo dominado y no le daría cabida a lo nacional-popular que sería construido desde abajo.

Mas, pienso, la paradoja se resuelve en tanto se razone que los movimientos nacionalpopulares son construidos tanto verticalmente como horizontalmente: estratégicamente con mayor presencia del primero (mediante el líder), pero reivindicando horizontalmente, ya que lo que está en juego es la reconfiguración de lo nacional-popular. Producto de lo 
anterior, y siguiendo con esta línea de análisis, quizás, no sería incoherente avanzar en calificar a un régimen de derecha como nacional-estatal, mientras que uno de izquierda podría ser catalogado de nacional-popular ${ }^{14}$. Pero como quiera que sea, lo importante es que en toda articulación populista intervengan tres elementos: el pueblo, en su carácter movilizador y antagónico, el líder y el reconocimiento ${ }^{15}$.

\section{Articulación hegemónica y rupturista de lo Popular}

En efecto, si se acepta la hipótesis presentada, el populismo ayudaría a la formación de lo nacional mediante la construcción de un pueblo que se articula, como bien señala Laclau, en torno a demandas no satisfechas, que lejos está de propiciar una lucha de clases, pero que sí pone en entredicho el rol hegemónico del grupo dominante-dirigente en la construcción de lo nacional. Es, a fin de cuentas, la conformación de un proyecto hegemónico, que busca dirigir y entregar, en último término, una nueva base social al Estado, en una disputa cultural en el que los conflictos sociales ya no serían únicamente de clase sino por las (re)interpretaciones de lo social.

Ahora bien, como se ha venido señalando, para Laclau el pueblo no tiene un contenido específico, pues sólo se constituye mediante una articulación discursiva. No obstante, en este punto, y como se señaló anteriormente, la propuesta de Laclau se torna un tanto problemática, por cuanto reconoce en dicha articulación la presencia de una plebs, es decir, aquella parte desvalida que busca ser reconocida y significada como "el todo" (Laclau, 2005). Ciertamente, el concepto plebs lleva a equívocos, ya que al mencionar Laclau que una parte es la desvalida de la sociedad, se quiera o no, le está otorgando una especie de contenido específico, un contenido de marginalidad. Se podría señalar en contra de esta aseveración que, para Laclau, basta con que una demanda no sea satisfecha para que ese grupo se convierta en marginal, pero bien se sabe que, en América Latina, ese marginal, ese no reconocido, viene siendo casi el mismo de siempre: el descamisado (Barros, 2014). En este sentido, sigo de cerca la propuesta de Aboy Carlés, quien más que reparar en el término plebs, rescata lo que según él es lo específico del populismo, esto es, la tensión antagónica entre un pueblo que quiere que se le reconozca como parte de la comunidad nacional: "el populismo es una forma política específica de procesar esa tensión entre la parte que se atribuye la representación legítima del todo y ese todo" (Aboy Carlés, 2010). Lógica hasta cierto punto indescifrable, asevera, Javier Burdman (2009), porque cuando esa parte logra integrar el todo, desde su inclusión impone exclusiones.

Como bien afirma Sebastián Barros (2006a, 2006b, 2009), lo que realmente identifica al pueblo, es su condición de parte excluida, de underdog, por lo que la ruptura populista siempre exigirá una interpelación a los de abajo, independientemente de que ésta sea

\footnotetext{
${ }^{14}$ Pero más allá de que se acepte o no esta última hipótesis, lo concreto es que en un régimen populista de derecha, en el caso latinoamericano, y asumiendo el riesgo de generalizar, la nación no es más que el pueblo no criollo, pero (re)presentado y simbolizado como un todo criollo. Mientras que, en el caso europeo, por el contrario, el populismo de derecha, acude y reivindica una definición étnica-cultural de carácter esencialista. En cambio, en un régimen populista de izquierda, independiente del lugar geográfico en que se haga el análisis, es el pueblo no representado el que exige ser reivindicado socioeconómica y políticamente revelándose éste como el verdadero todo. Y con ello se estaría matizando la tesis que esgrimen de Ípola y Portantiero (1981), quienes sostienen que no habría continuidad alguna entre populismo y socialismo, ya que, precisamente, el populismo sería la expresión material de un régimen burgués que apuesta por la movilización nacional-estatal en manos de un líder que inhibiría cualquier tipo de proceso revolucionario.

${ }^{15}$ Casullo, por ejemplo, apunta a que toda "unidad mínima de la movilización populista está formada por la tríada: líder, pueblo y movilización antagónica" (Casullo, 2014: 284).
} 
propiciada desde arriba, tal como lo concibe Weffort (1968). Pero si se conceptualiza al pueblo en una lógica interminable de demandas, como lo hace Laclau, la dificultad radicaría en que toda demanda no satisfecha sería configurable como populista, cuestión que le haría perder profundidad al término. Así, entonces, considero indispensable que se debe profundizar en lo específico de esa demanda, que en este caso la concibo como una demanda por reconocimiento y redistribución y no solo como justicia social, como supone Groppo (2009) ${ }^{16}$.

No pudiendo extenderme en mayores discusiones teóricas al respecto, asumo como modelo el planteamiento que hace Nancy Fraser, quien en su texto, Escalas de Justicia (2008), propone un modelo tridimensional para situar históricamente los conflictos por la justicia (Honneth, 1997, 2006). La autora distingue tres niveles. Un primer nivel, de tipo redistributivo, de asignación de bienes económicos; un segundo nivel, de reconocimiento, de existencia moral; y un tercer nivel, de representación, es decir, de tipo político (Fraser, 2008). Entonces, si se afirma que en una articulación populista se apela a un pueblo que está excluido de las decisiones soberanas de la nación, se exigirá, entonces, no sólo el reconocimiento político, sino también el económico y social ${ }^{17}$. El reconocimiento, entonces, es un acto moral de carácter antropológico que está anclado como acontecimiento cotidiano en el mundo social, pero que se define, esencialmente, por el conflicto y la conquista de los derechos, y que se enmarcan dentro de un proceso histórico que exige que los sujetos sean reconocidos (Honneth, 1997).

Es por estas razones expuestas, que la apelación al pueblo tiene siempre un carácter antagónico, de ruptura, movilizador. Para Barros (2009), el populismo es el momento de la irrupción de lo excluido. Por consiguiente, la idea de una inclusión radical significa que los discursos populistas también provocan una transformación en el orden institucional. Remitiéndose a Rancière (2011), Barros afirma que la inclusión de ciertas demandas en la discusión de una comunidad marca el comienzo de la política, pues ésta tiene que ver con el desacuerdo, el litigio de las partes dentro de una comunidad en las que el pueblo ha estado ausente y que ahora se erige como el todo comunitario. Según esta interpretación, entonces, al populismo habría que concebirlo como una movilización política que representa una forma específica de ruptura de la institucionalidad vigente mediante el planteamiento de un conflicto por la inclusión de una parte irrepresentable dentro de esa institucionalidad (Barros, 2009).

Al respecto, Javier Burdman (2009) acota que las interpelaciones y rupturas populistas, no siempre se ajustan a la irrupción del pueblo, por cuanto éstas incluso se pueden iniciar

\footnotetext{
${ }^{16}$ Por supuesto que Groppo (2009) tiene un punto importante cuando indica que la exigencia de "justicia social" es "él" elemento central en toda articulación populista. Ciertamente, pues si uno analiza distintos discursos de líderes populistas, su utilización es recurrente. Mas tengo dos dudas acerca de su uso. En primer lugar, respecto a qué variables pueden emplearse para definir con cierta precisión el término; en pocas palabras, para que éste no sea más que un recurso retórico ajeno a la realidad. Sobre todo, en la actualidad, donde no hay político que no haga uso del término, sin importar mayormente que sus políticas -incluso- propugnen un modelo (neo)liberal. En segundo lugar, como ya se ha señalado, no todos los regímenes populistas son de izquierda, por lo tanto, puede existir un régimen populista de derecha que utilice el término "justicia social" sin avanzar en reformas socioeconómicas profundas. En resumen, de utilizar el concepto, soy proclive a emplear el término post articulación, específicamente, cuando se hace referencia a un régimen de izquierda, aunque considero que el término más preciso es el de redistribución.

${ }^{17}$ Como juiciosamente argumenta Fraser (2008), lo que está en juego en el devenir social, no es sólo qué hay que considerar como genuino asunto de la justicia, si no, esencialmente, quién cuenta como auténtico sujeto de justicia. Vale la pena aclarar, para evitar largas disquisiciones teóricas, que durante la tesis se usa al reconocimiento como concepto genérico, aunque de un modo tridimensional, tal como lo plantea Fraser. Así, lo que ella llama representación yo lo llamaré participación; lo que sindica como reconocimiento lo denominaré reconocimiento discursivo, mientras que el término redistribución seguiré utilizándolo de la misma forma.
} 
en el momento que se resignifican los significados en términos antagónicos. Vale decir, una cosa es que la irrupción de lo heterogéneo exigiendo representatividad sea, como indica Barros, fundamental para el populismo, pero otra muy distinta, es manifestar que toda irrupción lleva consigo siempre ruptura al momento de hacerse efectiva. Así, para Burdman, si bien todo discurso populista se caracteriza por la presencia de una articulación equivalencial de demandas confrontadas con el orden dominante y la irrupción de otras demandas previamente marginadas en el orden institucional, no todas ellas aparecen en el momento de la irrupción (Burdman, 2009).

Entonces, lo que enseña Burdman son dos cosas. Primero, que lo específico del populismo se encontraría en la ruptura y no tanto en la irrupción de la heterogeneidad; y segundo, que el discurso populista podría no ser más que una resignificación disruptiva de discursos ya existentes e incluso que pudieron ser elaborados por otros. En efecto, "las interpelaciones populistas no surgen solamente como una ruptura del orden discursivoinstitucional relativamente consolidado, sino a la vez como una recuperación simbólica del momento real de la incorporación" (Burdman, 2009: 626). Bajo estas circunstancias, entonces, la pregunta a responder sería tratar de explicar por qué una interpelación populista está disponible en una sociedad determinada ${ }^{18}$.

La interpelación populista, por consiguiente, lejos está de otorgar entidad simbólica a actores que previamente se encuentran ausentes del discurso político, sino que más bien subvierte el sentido en el que dichos actores se hallan simbolizados. No existiría, entonces, heterogeneidad absoluta frente al ordenamiento anterior, porque siempre hay posibilidades de nueva reinterpretación. El punto, entonces, estaría en determinar por qué en ciertas sociedades no existe dicha posibilidad, pero, al mismo tiempo, como bien precisa Burdman en su crítica a Barros, si solo se enfatiza la irrupción disruptiva frente al orden institucional, se podría perder la perspectiva de entender al populismo como un régimen que, en definitiva, busca institucionalizarse.

\section{Institucionalidad Sucia}

El populismo, entonces, no solo exigiría movilización, sino que también requiere de una institucionalización ad hoc. En efecto, suscribo a la tesis propuesta por Aboy Carles, en el sentido de que no es posible realizar una separación radical entre lógica de la diferencia y de la equivalencia, pues no hay evidencia empírica que permita demostrar que lo institucional (diferencial) se mantiene puro o que la ruptura sea la quintaesencia de lo equivalencial, pues si se separan tan radicalmente ambos fenómenos, se estaría rechazando de plano la negociación entre las identidades sedimentadas (institucionales) y emergentes (populistas) a través de un juego de inclusiones y exclusiones del campo adversario (Aboy Carlés, 2010; Aboy Carlés y Melo, 2014).

Pese a que las identidades populistas emergen -siempre- como una impugnación al orden institucional y se presentan con un ánimo fundacional que deslegitima toda identidad sedimentada, lo cierto es que ese aparente todo, choca con la resistencia de identidades ya

\footnotetext{
${ }_{18}$ Plantea Burdman (2009) que, en un contexto de descrédito general de los discursos políticos tradicionales, los discursos de tipo populista presumiblemente podrían tener una mayor acogida, pero a no engañarse: pues su aceptación y consiguiente legitimidad dependerían, en último término, que dicha interpelación populista sea percibida como auténtica y no como demagógica.
} 
institucionalizadas. En efecto, no habría nada parecido a un "vaciamiento del campo político", pues la aparición de esta nueva identidad que se arroga la verdadera representación del populus, no es más que un discurso fundacional que oculta las continuidades existentes entre la nueva identidad y el orden político previo (Aboy Carlés, 2003). En consecuencia, el populismo (en tanto movilización) y el institucionalismo, como lo demuestra Melo (2012), son dos extremos de un mismo continuum.

La paradoja es evidente, pues, por un lado, si la intensidad de ruptura se exacerba, no habría ya espacio para la negociación y el enfrentamiento social sería la única alternativa, pero, por otro, si se apunta a la continua institucionalización de la ruptura, la nueva identidad emergente perdería su carácter radical que la definió desde el momento de su irrupción. Pareciera ser que no hay salida posible. Tal como lo afirma Aboy Carlés (2003, 2010), el costo de seguir entendiendo un recurrente mecanismo de inclusión y exclusión, terminaría generando una constante inestabilidad del demos que haría imposible una institucionalización pluralista futura. Tampoco se podría esperar la existencia prevalente y casi excluyente de una u otra lógica, ya que, en último término, socavaría todo tipo de movimiento nacional popular (Ostiguy, 2015). De hecho, en este ámbito, la propuesta de Ostiguy es que movilización e institucionalidad deben combinarse "en una sola lógica". Es lo que el autor denomina "Institucionalidad sucia", siendo ésta, quizás, uno de los principales elementos que haría particular al populismo y que lo diferenciaría de la gramática de lo alto, esto es, el predominio de la híper-institucionalización, cuestión que impediría el advenimiento del populismo (Ostiguy, 2014).

En definitiva, me alejo del argumento que plantea una oposición insalvable entre populismo e institucionalismo, provenga del neo-institucionalismo o del mismo Laclau, pues parto de la base que la ruptura antagónica se produce, fundamentalmente, por una debilidad -en el caso particular de Latinoamérica- estructural en la constitución democrática del Estado nacional, que impulsa al pueblo representado a través de un líder a demandar una mayor participación social, económica y política.

\section{El líder Populista}

Entonces, la característica invariante de todo populismo reside en que es un fenómeno ideológico en el cual las interpelaciones popular-democráticas se articulan y se presentan hegemónicamente bajo la forma de un antagonismo irreductible respecto a la ideología dominante, en donde la construcción del pueblo se efectúa en y como discurso en un plano relacional objetivo, bajo la dirección (desde arriba, mas nunca absoluta) siempre presente de un líder, quien confiere cohesión a la heterogeneidad del grupo e irrumpe en el espacio público para fijar la unidad de una formación social (Laclau, 2005). El líder populista, entonces, asume como ruptura dislocando el espacio, y pese a que puede provenir del grupo dirigente, lo distintivo es que se presenta en oposición antagónica a dicho grupo. En este sentido, a la vista de detractores y seguidores, se presenta como un outsider político, pese a que pueda haber formado parte -o ser parte en el momento de la irrupción- del poder institucionalizado.

Ahora bien, no todo discurso que contenga la palabra pueblo es por defecto populismo, pues de señalar esto, todo discurso que apele al pueblo sería populista o al menos tendría un 
rasgo populista ${ }^{19}$. Así, entonces, solo se puede hablar de populismo cuando existe una ruptura antagónica que coloca al pueblo como sujeto político fundamental en oposición a otro, aunque, por cierto, el riesgo que dicha apelación no sea más que retórica está siempre presente. Y ciertamente que no se requiere construir un complejo sistema de variables para determinar esto último, pues bastaría con observar de qué modo cobra relevancia la ruptura.

Tomo distancia también de todas aquellas teorías que esbozan que el líder no es más que un caudillo clientelar con un estilo demagógico ${ }^{20}$. O que el populismo es, simplemente, una estrategia que utilizan líderes personalistas sin apelar a ninguna ideología específica para llegar al poder. No obstante lo anterior, no se puede desconocer que, en no pocas ocasiones, líderes populistas se transformaron en gobernantes autoritarios, personalistas, o como manifiesta Weffort, manipuladores oportunistas, pero, con todo, dicha manipulación nunca fue absoluta, "pues si lo hubiera sido se estaría obligado a aceptar la visión liberal de las elites que, en última instancia, ve en el populismo una especie de aberración de la historia alimentada por la emocionalidad de las masas" (Weffort, 1968: 56).

Comparto con Laclau (2006) la idea de que siempre hay un riesgo de que este líder limite severamente la participación $\operatorname{popular}^{21}$. Pero como quiera que sea, aún si el populismo, en ocasiones, ha sido un modo determinado y concreto de manipulación de las clases populares, fue y ha sido también un modo de expresar sus insatisfacciones (Weffort, $1968)^{22}$. La cuestión, entonces, va más allá de establecer si un líder populista ha hecho uso de su carisma o ha presentado un discurso con fines estratégicos electorales. En el fondo, el problema está en afirmar que solo ellos lo hacen. Una cosa es que dichas anomalías, en un determinado momento, se puedan atribuir a algunos líderes, pero otra es decir que son exclusivas y excluyentes de líderes populistas ${ }^{23}$. En definitiva, por más que en la conformación del populismo la figura del líder sea controversial (por sus rasgos autoritarios, manipuladores), lo cierto es que su liderazgo, como argumenta Rodríguez, "será pensado, dada su inscripción en un contexto histórico-institucional, como la

\footnotetext{
${ }^{19} \mathrm{El}$ enfoque ideacional, que propugna una definición mínima de populismo, está muy cerca de afirmarlo, porque para dicho enfoque el populismo es una thin-centered ideology, que opone al pueblo frente a quienes subvierten la voluntad popular, esto es, las elites de todo tipo (Rovira, 2013). Con todo, tal como argumenta Weyland (tras una conversación que sostuve con él), medir en distintos discursos como constante principal- el uso del término pueblo, puede generar más falsos positivos que ayudar a fijar con precisión el concepto.

${ }^{20}$ Como bien plantea Benjamín Arditi (2011b), en directa critica al enfoque del estilo, si todo aquello que se refiere al estilo populista es, ni más ni menos, la utilización del lenguaje simple y directo para atraer a los votantes, sería ese y no otro el modo característico de la política contemporánea, es decir, dicho estilo no sería algo exclusivo del populismo. Argumenta, además, que si la apelación populista al pueblo contiene solo demagogia, la dificultad estribaría en que concurrirían tantos elementos que harían casi imposible medirlo.

${ }^{21}$ Así también, Benjamín Arditi opina que los líderes populistas asumirían, en no pocas ocasiones, una re-presentación de inmediatez con el pueblo, pues al intentar borrar la brecha entre representantes y representados, "se funda en una oscilación ambivalente entre la glorificación de la acción independiente del pueblo, donde el líder es solo su portavoz o vehículo, y una apropiación instrumental de dicha acción en la que el líder habla por el pueblo" (Arditi, 2011b: 133).

${ }^{22}$ Sin embargo, Weffort es claro al afirmar que la manipulación populista entre el líder y la masa es siempre ambigua, ya que "desde un punto de vista político es, por un lado, una relación de identidad entre individuos, entre el líder que dona y los individuos que componen la gran masa de asalariados y, por otro, es una relación entre el Estado como institución y determinadas clases sociales" (Weffort, 1968: 75).

${ }^{23}$ Por su parte, Vilas (1995a) indica que el líder populista surge por factores objetivos, principalmente, por la necesidad de un nuevo estilo político de dominación que incluye, por una parte, la manipulación de las masas, y por otro, algún grado de satisfacción y conciliación de sus intereses económicos y aspiraciones políticas y sociales. Es esta condición la que explicaría, según Vilas, la ambigüedad intrínseca que le acontece al líder populista. Con todo, Vilas está muy lejos de concebir al líder populista, como lo impuso la tradición marxista latinoamericana, como un líder cesarista o bonapartista, pues si bien hay una relación multitudinaria entre el líder y la masa, que se caracteriza por el culto a la personalidad y donde se perciben, además, actitudes autoritarias por parte del líder, la gran diferencia con el cesarismo y el bonapartismo, es que durante el populismo hubo procesos efectivos de consolidación democrática. Sostiene, entonces, que se sindique al culto de la personalidad, el autoritarismo y el clientelismo, como fenómenos exclusivos y excluyentes del populismo, es un despropósito.
} 
existencia de un lazo político entre los representantes y los representados en razón de la cual se establecen los sentidos que organizan, siempre transitoriamente, toda comunidad política" (Rodríguez, 2014: 638).

El populismo es, ante todo, una articulación que, si bien no es identificable con la democracia ni mucho menos con la política, como lo sostiene Laclau, viene a ser un acto performativo de la realidad social, dotado de una racionalidad propia que simplifica el espacio político en dos dicotomías antagónicas, cuyos dos polos son necesariamente imprecisos y en el que los actores se ven a sí mismos como partícipes de uno u otro de los dos campos enfrentados y que exigen ser reconocidos. El populismo, entonces, siempre hará exigible la división social, en donde un sector de la sociedad se presentará a sí mismo como la expresión y la representación de la comunidad como un todo. El pueblo, por lo tanto, sólo es constituido en el terreno de las relaciones de representación, en el que una determinada particularidad terminará asumiendo una función de representación universal.

\section{La Crisis hegemónica}

Ahora bien, la noción de crisis es clave para explicar al populismo, en el entendido que no toda crisis desemboca necesariamente en un populismo, pero sí exige al menos su presencia. De hecho, gran parte de la academia supone que el populismo, justamente, se produce en períodos de crisis, cuestión que, según Alan Knight (2005), carece de rigor explicativo. Para el autor, la crisis, en el mejor de los casos, es una tendencia o correlación, no un requisito específico o un criterio esencial definidor, pues el populismo se podría manifestar en tiempos normales y no críticos, y no sólo eso, pues, en ocasiones, sería el populismo el que generaría la crisis (Knight, 2005). Sin embargo, todo parece indicar que el problema de Knight con la utilización del término crisis, dice relación con la vacuidad que ha alcanzado el concepto. Una cosa es que se haga un uso despectivo del término crisis, pero otra muy distinta es considerar que la crisis, entendida como crítica, sea del todo ajena al populismo. Crisis sociales, económicas o políticas, por supuesto que son incentivos para la gestación de un fenómeno populista. Así, en mi opinión, el problema se resume en que hábilmente los detractores del populismo lo presentan como el mayor peligro que trae aparejado -cuando no produce- toda crisis ${ }^{24}$.

Pero cuando se hace referencia a un proceso populista, el término crisis asume un rol fundamental, sobre todo, cuando va acompañado de un proyecto contra-hegemónico. En rigor, una cosa es hacer mención a una crisis, y otra distinta, a una crisis hegemónica, pero habría que precisar que ello no significa que ambas crisis se confronten; de hecho, muchas veces se complementan, o más propiamente, pueden llegar a articularse. A decir verdad, quienes por primera vez utilizaron el término con relación al populismo, lo hicieron siempre desde un contexto de modernización, esto es, del paso de una sociedad tradicional (rural) a una moderna (urbana-industrial), centrándose en los efectos que ocasionaron la movilización social y política de los grupos recién llegados a la ciudad en un contexto de crisis hegemónica, fenómeno que vino poner fin a la dominación oligárquica decimonónica

\footnotetext{
${ }^{24}$ Ciertamente que la paradoja es evidente, pues es el propio sistema político-económico el que defenestra la crisis como signo populista sin asumir las propias limitaciones de todo sistema.
} 
(Ianni, 1975; Weffort, 1968) $^{25}$. Con todo, y pese al magnífico análisis que realizan, la dificultad de la propuesta de Ianni (1975) y Weffort (1968), es que ésta deja inmóvil en el tiempo el término crisis hegemónica al período del Estado Desarrollista o Populista.

En términos gramscianos ${ }^{26}$ entiendo por crisis hegemónica, una crisis de legitimidad política y valórica que cuestiona, al mismo tiempo, el modelo de desarrollo y/o de acumulación; es decir, la forma en que se produce y se distribuye la riqueza. Una crisis hegemónica, entonces, se explica, sí y solo sí, está en discusión el bloque histórico de poder y no cuando se produce una simple crisis de legitimidad de éste. Una crisis hegemónica obedece, por tanto, a factores estructurales más que agenciales, aunque no se desconoce el hecho de que un factor en particular (el líder, una demanda) pueda constituirse como el desencadenante principal de una crisis larvada u obturada. Afirmar, entonces, que una crisis hegemónica puede encontrarse obturada es de principal interés teórico, ya que no toda crisis hegemónica supone necesariamente un vacío de poder "político". En breve, puede que los sucesos históricos que han desencadenado procesos populistas, especialmente en el caso argentino, presenten como una constante dicha situación, mas apelar únicamente al vacío de poder (institucional) para explicar una crisis hegemónica puede hacer olvidar su dimensión socio-económica. De todos modos es prudente afirmar que cuando se hace referencia a elementos estructurales, no por ello se está propugnando un análisis "estructuralista" de corte esencialista, sino que se está defendiendo la idea que toda articulación populista responde a condiciones de posibilidad que se desarrollan en el longue durée $e^{27}$.

Por cierto que el desarrollo de una crisis hegemónica, no es una condición suficiente para que se desarrolle un proceso populista, porque, en primer lugar, una crisis hegemónica podría conllevar el cambio de todo el sistema político, por lo que ya no se estaría ante una experiencia populista, sino que una de tipo revolucionaria (marxista) o incluso fascista; en segundo lugar, una crisis hegemónica no necesariamente puede producir el ascenso de nuevos grupos dirigentes, sino tan sólo un reacomodo de éste grupo o un interregno mediante una dictadura. Así entonces, esta aproximación teórica excluye a movimientos revolucionarios, pues en ellos la movilización, generalmente desde abajo, ha conducido a una reestructuración total de las relaciones de dominación y de producción, aunque no por ello el populismo debería ser calificado (tal como insiste una línea teórica de izquierda) como un simple acomodo de los grupos de poder. Sostiene Nicos Mouzelis:

\footnotetext{
${ }^{25}$ Así, según Weffort (1968), el populismo latinoamericano se habría desencadenado porque ninguno de los actores sociales involucrados -en tanto clases- dieron una respuesta efectiva a los problemas de legitimidad, de crisis hegemónica, que acompañó al fin del Estado Oligárquico (1930-1940), y que se tradujo en una movilización popular que gatilló la creación de un nuevo proyecto nacional que reconocía tanto política como socialmente grupos sociales que durante siglos no habían sido reconocidos. Es en este contexto de vacío de poder, en el que habría irrumpido el líder populista, quien operó políticamente entre las distintas fuerzas sociales, asumiendo el papel de eje de la alianza multiclasista, aun cuando ésta, en la práctica, haya sido de corto plazo y meramente programática (Vilas, 1995b).

26 Antonio Gramsci (1966) utilizó los conceptos de crisis orgánica, hegemonía e ideología para poder explicar, aunque no sistemáticamente, la noción de crisis hegemónica. Según el autor, una ideología se torna hegemónica cuando una clase es capaz de asegurar la adhesión y el consentimiento de las masas. Así, en un primer sentido, el autor habla de hegemonía para referirse a los mecanismos usados por la burguesía para mantener (sin recurrir sistemáticamente a la violencia) su control cultural e institucional sobre la clase obrera, y en segundo término, para referirse a la capacidad que tiene esta última de formar alianzas con otras clases no dominantes. En términos gruesos, se puede afirmar que, para el autor, una crisis orgánica se produce cuando una clase dirigente pasa a convertirse en pura clase dominante, al imponer su horizonte normativo mediante dominio y no por consenso. Crisis de autoridad de las clases dirigentes en el que las clases subalternas disputarían su hegemonía cultural, pudiendo así alterar el bloque histórico de poder (Gramsci, 1966: 50).

${ }^{27}$ Término elaborado y definido por la Escuela de los Annales, que propugna una nueva forma de entender la Historia y que separa los procesos históricos en acontecimientos, media duración y larga duración (Burguiere, 2010).
} 
... debido, en parte, a que el concepto del populismo no entraña la noción de una transformación total de una sociedad, es empleado de forma peyorativa por sectores de izquierda revolucionaria. Pero también, excluye, en el otro extremo, a los dirigentes que movilizan al pueblo a fin de alcanzar metas de corto plazo, y en ese caso, no hay transformación relevante en las relaciones de dominación ni de producción. En consecuencia, entre los dos extremos no-populistas, los movimientos populistas han tenido éxito en la efectiva movilización de las masas, tanto en regímenes parlamentarios como no parlamentarios, generando una ampliación de la participación política y esa ampliación siempre involucra alguna reestructuración permanente del modo en que los grupos dominantes y dominados se relacionan recíprocamente. Denomino populista al movimiento que conduce a tal reestructuración, así como a la forma de régimen adoptada por esa misma" (Mouzelis, 1995: 479480).

En resumen, se está ante la presencia de una crisis hegemónica cuando se critica en forma profunda, el modelo político y económico imperante. Es en dicho período cuando se inquiere si el orden vigente es el resultado del consenso, del recorrido histórico y deliberativo de una sociedad. Se constituye, entonces, esencialmente, como una profunda crisis política, de legitimidad institucional y de quiénes se encuentran en la cúspide del poder, aunque también es una crisis económica, pues es el resultado de una puesta en juicio del modelo de desarrollo, específicamente, un cuestionamiento de cómo se produce, distribuye, y sobre todo, acumula. Me separo, por tanto, de quienes circunscriben la crisis hegemónica, en lo económico, a la crisis que afectó al modelo primario exportador (1930), pues de ser así, el populismo se vería limitado a un momento específico de la historia latinoamericana. Al mismo tiempo, prefiero hablar de modelo de desarrollo que de acumulación (a secas), debido a que este término puede llevar a equívoco, por cuanto, se quiera o no, tal término guarda relación directa con el concepto de plusvalía (Salazar, 2003). En rigor, "el populismo es un tipo de movilización política que entraña una reestructuración radical de las relaciones prevalecientes de dominación, sin una transformación concomitante de las relaciones de producción” (Mouzelis, 1995: 479).

\section{Conclusión}

Como se señaló, este trabajo no tiene como objetivo central, que los académicos renuncien a conceptualizar al populismo desde un enfoque determinado. De hecho, el artículo se inicia destacando el aporte de Laclau respecto a la noción del populismo como lógica, y al mismo tiempo, la forma en que dicha lógica es construida. Para Laclau, el populismo se define como una articulación discursiva que se caracteriza por el antagonismo; precisamente, porque designa el límite de la objetividad social, que es el lugar en el que el pueblo se constituye mediante un "juego" discursivo en oposición al bloque de poder. En este sentido, se puede afirmar que Laclau busca, ante todo, determinar la forma en cómo es construida la lógica populista y no indagar qué condiciones de posibilidad o contenidos puede tener, pues, como argumenta, el populismo en tanto fenómeno de la lógica social, no es más que el auténtico modo de constituir lo político. 
Ahora bien, sostener que el populismo es, en términos simples, una articulación discursiva, plantea un problema de fondo en relación a cómo se aplicaría dicha construcción teórica a la experiencia histórica-social. Ante esto, se afirma que una primera dificultad, sería explicar por qué contenidos ideológicos diversos pueden ser catalogados indiferentemente como populistas sin distinguir entre contenidos que podrían hacer radicalmente diferente a un populismo de otro. Una segunda dificultad, que es donde centra su análisis el presente trabajo, consiste en profundizar la propuesta de Laclau a nivel teórico, sobre todo, si ésta tiene por objeto lograr su aplicación empírica. Así, en primer lugar, habría que dejar de lado la premisa lacluniana que considera al populismo como el espacio donde se define ineluctablemente la política y la hegemonía. En segundo lugar, se debería tratar de compatibilizar aún más ruptura con institucionalidad, pues para llegar a entender correctamente el populismo, no solo debería importar su articulación, sino que, ante todo, asumir que se debe constituir como régimen de gobierno. Esto último es particularmente importante, pues si la apuesta futura es que los populismos se definan tanto por su articulación como por contenidos, al momento de calificarlos, ya no sólo se trataría de mostrar la existencia y la articulación de una lógica populista, sino que, progresivamente, el problema apuntaría a establecer una exploración empírica de los populismos "realmente existentes". Pero como quiera que sea, fue Laclau el que abrió brillantemente el camino.

En rigor, lo que se propone este estudio, es concebir al populismo como un proceso histórico que obedece a distintas condiciones de posibilidad. De hecho, se invita a reflexionar acerca del populismo respecto a sus condiciones de posibilidad de tipo estructural (sin que por ello se realice un análisis puramente estructuralista) y agencial, evitando así definir al "fenómeno" solo como la lógica de la política, aunque rescatando la idea de que el populismo es una dimensión de la política (Worsley, 1969; Laclau, 2005). Se propone, entonces, estudiar al populismo desde una perspectiva sociológica-histórica y no episódica. Llamar a un "fenómeno populista" desde uno u otro enfoque no está en discusión (aunque acá se asume el político-discursivo), sino el verificar que un fenómeno populista se desencadena tras un momento populista, y que luego, puede constituirse en un régimen que responde a distintos contenidos (derecha o izquierda).

Se afirma que todo proceso populista nace a partir de una crisis hegemónica, ya sea que ésta se encuentre obturada, larvada o en pleno desarrollo. Sin embargo puede ocurrir que un discurso pueda ser catalogado de populista porque reúne características "objetivas" que le permitan llevar ese apelativo (porque hay un líder que se dirige a las masas y porque hay un claro discurso antagónico que separa al pueblo del bloque de poder, entre otras cosas), pero lo que realmente debería importar al momento de constatar la presencia o no de populismo, es si efectivamente el discurso que se enuncia resume una articulación discursiva que intenta o lleva a cabo un proyecto contra-hegemónico. Y esto es solo posible de verificar si se entiende al populismo como un proceso. Ciertamente que el discurso político resalta como el principal elemento, si se quiere verificador, de la presencia de una articulación populista. Con todo, esto no significa que sea el discurso el que determina por sí solo si se está ante la presencia o no de populismo. Vale decir, un discurso puede ser caracterizado como populista (solo por su articulación), pero no por ello se está ante un proceso populista. Cuestión distinta es que dicho discurso se articule como acicate o resultado de 
una crisis hegemónica, pues solo ahí se da inicio a un proceso populista (en tanto fenómeno), aunque no por ello el proceso se cerrará -siempre- con la consolidación de un régimen.

En este sentido, es preciso reparar en la apuesta que hace Pelfini (2015) en relación a la existencia de un momento populista, es decir, al contexto de una crisis hegemónica que vendría siendo el gatillante principal del populismo. Con todo, y pese a la presencia de objetivas condiciones que podrían dar lugar a un proceso populista, puede ocurrir que producto de estructuras, repertorios y ausencia de liderazgos, dicho momento no cristalice como fenómeno ni mucho menos como régimen. Un fenómeno populista, en tanto, requiere de dos condiciones para su existencia: una crisis hegemónica y una articulación populista. Así, entonces, lo que resulta decisivo a la hora de hablar de un fenómeno populista, es que se produzca una articulación populista; esto es, que exista una interrelación necesaria y suficiente entre pueblo, líder, irrupción-ruptura, movilización y reconocimiento, en un contexto de crisis hegemónica (presente o incubada) y en tanto el discurso adquiera una dimensión contra-hegemónica. Con todo, una articulación populista se puede generar sin que quien la propugne llegue al poder, mientras que un régimen populista exige de su presencia. Pero, sobre todo, un régimen populista a diferencia de un fenómeno populista, exige que se haga efectivo política e institucionalmente su contenido; pero a su vez, que no sea meramente movilizador o institucional, sino una combinación entre ambas lógicas (Ostiguy, 2014). Todo el esfuerzo anterior, no puede ser visto como una simple tipología, pues, en mi opinión, resulta vital para precisar el concepto, por cuanto el populismo es un tipo de discurso político (en tanto dimensión de la política) que, como régimen, se ha dado en contados y específicos momentos de la Historia. Lo que puede haber existido, quizás, y en no pocas ocasiones, son momentos populistas, pero no así fenómenos que hayan concluido en regímenes populistas. En definitiva, resulta perentorio separar tres esferas distintas en lo que se puede denominar un "proceso populista total": primero, la presencia de una crisis hegemónica (el momento populista); segundo, que dice relación al tiempo en que se produce la articulación populista (el fenómeno populista) y, por último, el proceso de obtención del poder (el régimen populista).

\section{Bibliografía}

Aboy Carlés, G. (2003). Repensando el Populismo. Política y Gestión, 4, 9-34.

(2005). La democratización beligerante del populismo. Centro de Estudios del Discurso y las Identidades Sociopolíticas, Escuela de Postgrado de la Universidad de San Martín/CONYCET. Disponible en: http://historiapolitica.com/datos/biblioteca/aboycarles.pdf (Consultado en línea: 5 de septiembre de 2015)

(2010a). Las dos caras de Jano: acerca de la compleja relación entre populismo e instituciones políticas, Pensamento Plural, Pelotas (07), 21-40.

(2010b). Populismo, regeneracionismo y democracia. Postdata 15 (1), 11-30.

Aboy Carlés, G. y Melo, J. (2014). La democracia radical y su tesoro perdido. Un itinerario intelectual de Ernesto Laclau, Postdata 19 (2), 395-427. 
Aibar, J. (2008). Sobre alquimistas e imaginadores. Populismo y nación. En C. De la Torre y E. Peruzzotti. El retorno del pueblo. Populismo y nuevas democracias en América Latina. (pp. 161185) Quito: Flacso.

Arditi, B. (2011a). El populismo como espectro de la democracia. Respuesta a Canovan. En B. Arditi, La política en los bordes del liberalismo. Diferencia, populismo, revolución, emancipación (pp. 107-119). Barcelona: Gedisa.

(2011b). El populismo como periferia interna de la política democrática. En B. Arditi, La política en los bordes del liberalismo. Diferencia, populismo, revolución, emancipación (pp. 121158). Barcelona: Gedisa.

Barros, S. (2006a). Inclusión radical y conflicto en la constitución del pueblo populista. Revista Confines, 2, (003), 65-73.

(2006b). Espectralidad e inestabilidad institucional. Acerca de la ruptura populista. Revista de Estudios Sociales, (30), 145-162.

(2009). Salir del fondo del escenario social: sobre la heterogeneidad y la especificidad del populismo. Revista Pensamento Plural, Pelotas (05), 11-34

(2014). Momentums, demos y baremos. Lo popular en los análisis del populismo latinoamericano. Postdata 19 (2), 315-344.

Biglieri, P. y Perelló, P. (2015). Sujeto y Populismo o la radicalidad del Pueblo en la teoría postmarxista. Debates y Combates, 1 (9), 53-63.

Burdman, J. (2009). Heterogeneidad, irrupción radical y mito en la génesis de las interpelaciones populistas durante la conformación del peronismo. Revista SAAP, 2 (3), 615-634.

Burguiere, A. (2010). La Escuela de los Annales. Una historia intelectual. Valencia: Universitat de Valencia.

Cancino, H. (2008). La reemergencia del discurso nacional-popular en la nueva izquierda latinoamericana. Para una discusión de los movimientos nacional-populares. Diálogos Latinoamericanos (013).

Casullo, M. (2014). ¿En el nombre del Pueblo? Por qué estudiar al Populismo Hoy, Postdata 19 (2), 277-313.

Conniff, M. (2003). Neopopulismo en América Latina: la década de los 90 y después. Revista de Ciencia Política, 23 (1), 31-38.

Conniff, M. (2012). Populism in Latinamerica. Alabama: University of Alabama Press.

De Ípola, E. y Portantiero, J. (1981). Lo Nacional popular y los Populismos realmente existentes. Nueva Sociedad (54), 7-18.

Disch, L. (2015). Ernesto Laclau y el "redescubrimiento" democrático de la representación. Debates y Combates. 1 (9), 33-48.

Di Tella, T. (1965). Populismo y reforma en América Latina. Desarrollo Económico 4 (16), 391425.

Dornbush, R. y Edwards, S. (1991). The Macroeconomics of Populism in Latin America. Chicago: University of Chicago Press.

Edwards, S. (2009). Populismos o mercados: el dilema de América Latina, Colombia: Norma.

Fraser, N. y Honneth, A. (2006).Redistribución o reconocimiento. Un debate político- filosófico. Madrid: Morata.

Fraser, N. (2008). Escalas de Justicia. Barcelona: Herder.

Freidenberg, F. (2007). La tentación populista, una vía al poder en América Latina. Madrid: Síntesis. 
Freud, S. (2010). Psicología de las Masas. Madrid: Alianza.

Germani, G. (1965a). Política y sociedad en una época de transición: de la sociedad tradicional a la sociedad de masas. Buenos Aires: Paidós.

(1965b). Democracia representativa y clases populares en América Latina. En G. Germani y A. Touraine, América del Sur: un problema nuevo. Barcelona: Nova Terra.

Groppo, A. (2009). Los dos príncipes: Juan D. Perón y Getulio Vargas. Buenos Aires: Eduvim.

Hermet, G. (2003). El populismo como concepto. Revista de Ciencia Política XXIII (1), 5-18.

(2008). El invierno de la democracia. Auge y decadencia del gobierno del pueblo.

Barcelona: Los libros del Lince.

Honneth, A. (1997). La lucha por el reconocimiento. Una gramática moral de los conflictos sociales. Barcelona: Crítica.

Ianni, O. (1975). La formación del Estado populista en América Latina, México: Era.

Knight, A. (2005). Revolución, Populismo y democracia en América Latina. Chile: PUC.

Laclau, E. (1986). Política e ideología en la teoría marxista: capitalismo, fascismo y populismo. Madrid: Siglo XXI.

Laclau, E. (2005). La razón populista. Buenos Aires: Fondo de Cultura Económica.

$56-61$.

(2006). La deriva populista y la centroizquierda latinoamericana. Nueva Sociedad (205),

(2009). Populismo, ¿qué nos dice el nombre? En F. Panizza (comp.), El populismo como espejo de la democracia (pp. 51-70). Buenos Aires: Fondo de Cultura Económica.

Laclau, E. y Mouffe, Ch. (2010). Hegemonía y estrategia socialista. Buenos Aires: Fondo de Cultura Económica.

Martínez, M. y Vaisberg, R. (2014). La narrativa revolucionaria del chavismo. Postdata 19 (2), 464-506.

Melo, J. (2008). La democracia populista: Populismo y democracia en el primer peronismo. Pensamiento Plural 3, 23-42.

Melo, J. (2011). Hegemonía populista, ¿Hay otra? Nota de interpretación sobre populismo y hegemonía en la obra de Ernesto Laclau. Revista electrónica semestral Instituto de Estudios Sociales 1, 48-69.

Mouffe, C. (2016). Podemos: El momento populista. Opinión, Diario El País. Disponible en: http://elpais.com/elpais/2016/06/06/opinion/1465228236_594864.html (Consultado el 12 junio de 2016).

Mudde, C. (2004). The Populist Zeitgeist. Government \& Opposition 39 (3), 541-563.

Mudde, C. y Rovira, C. (2011) Voices of the peoples: populism in Europa and latinamerican compared, Working paper 378, KELLOGG INSTITUTE.

(2012) Populism and (Liberal) Democracy: A Framework for Analysis. En

C. Mudde, C. Rovira, Populism in Europe and the Americas, Threat or Corrective for Democracy (pp. 1-26). Cambridge: University Press.

(2017) Populism. A Very Short Introduction, Oxford: University Press.

Mouzelis, N. (1995) Populismo y clientelismo como modos de incorporación de las masas en sistemas políticos semiperiféricos, En C. Vilas (comp) La democratización fundamental. El populismo en América Latina, (pp. 459-480). México: Consejo Nacional para la cultura y las artes. Orlandi, E. (2012) Análisis de Discurso. Principios y procedimientos. Santiago: LOM.

Ostiguy, P. (2014) Exceso, representación y fronteras cruzables: "Institucionalidad sucia" o la aporía del Populismo en el Poder. Postdata 19 (2), 345-375.

(2015) Gramáticas plebeyas: exceso, representación y fronteras porosas en el populismo oficialista. En C. Véliz y A. Reano (comp.) Gramáticas Plebeyas. Populismos, 
democracias y nuevas izquierdas en América Latina, (pp. 133-177). Buenos Aires: Universidad Nacional de General Sarmiento,

Pelfini, A. (2015) Megatrend Global Populism?: From South America to the Occupy Movement. En A. Lenger y F. Schumacher (comp.): Understanding the Dynamics of Global Inequality, (pp. 197209). Heidelberg/New York: Springer.

Quiroga, M. (2014) Debates y recepciones de la perspectiva laclusiana del populismo. Pueblo e instituciones en los discursos populistas latinoamericanos. Postdata 19 (2), 377-394.

Rancière, J. (1996) El desacuerdo, política y filosofía. Buenos Aires: Nueva Visión. (2006) Política, policía, democracia. Santiago: LOM.

Roberts, K. (1995) Neoliberalism and the Transformation of Populism in Latin-America: The Peruvian Case. World Politics 48 (1), 82-116.

Roberts, K. (2009) Beyond Neoliberalism: Popular Responses to Social Change in Latin America. EnJ. Burdick, P. Oxhorn, y K. Roberts (comp.) Beyond Neoliberalism? Patterns, Responses, and New Directions in Latin America and the Caribbean. (pp. 1-13)New York: Palgrave-MacMillan.

Rodríguez, D. (2014) Populismo y liderazgo en la democracia argentina. Un cruce comparativo entre el menemismo y el kichnerismo. Postdata 19 (2), 637-680.

Rovira, C. (2012) The Ambivalence of Populism: Threat and Corrective for Democracy. Democratizacion 19 (2), 184-208.

$62(3)$.

(2013) The responses of Populism to Dahl's Democratic Dilemmas. Political Studies

Tarizzo, D. (2015) Masa y pueblo: Freud y Laclau. Debates y Combates 1 (9), 103-111.

Vilas, C. (1995a) El populismo latinoamericano: un enfoque estructural, En CARLOS VILAS (comp.), La democratización fundamental. El Populismo en América Latina. México: Consejo Nacional para la cultura y las artes.

(1995b) Prólogo. En C. Vilas (comp.), La democratización fundamental. El Populismo en

América Latina. México, Consejo Nacional para la cultura y las artes.

Walker, I. (2006) Democracia en América Latina. Foreign affairs en español 6 (2), 2006

(2009) La democracia en América Latina: entre la esperanza y la desesperanza.

Santiago: Uqbar-Cieplan.

Weffort, F. (1968) "El populismo en la política brasilera". En C. Furtado (comp.) Brasil Hoy, México: Siglo XXI.

Weyland, K. (1999) Neoliberal populism in Latin America and Eastern Europe. Comparative Politics 31 (4), 1999, 379-401.

(2001) Clarifying a contested concept: Populism in the study of Latin American politics. Comparative Politics 34 (1), 1-22.

(2003) Neopopulism and Neoliberalism in Latin America: How Much Affinity?, Third World Quarterly 24 (6), 1095-1115.

(2004) Neoliberalism and Democracy in Latin America: A Mixed Record. Latin American Politics and Society 46 (1), 135-157.

Worsley, P. (1969) "El concepto del populismo", En G. Ionescu, E. Gellner (comps.), Populismo (pp. 259-304). Buenos Aires: Amorrortu. 